In practice consideration for referral for venting gastrostomies is guided by local surgical practice.

Conclusion(s) There is a paucity of evidence with regards to medical management of $\mathrm{MBO}$, much more is required. Subsequent to this review, new local guidelines have been developed.

\section{P 041 MALIGNANT BOWEL OBSTRUCTION-A SYSTEMATIC LITERATURE REVIEW AND EVALUATION OF CURRENT PRACTICE}

E Longford, A Scott, S Fradsham, C Jeffries, F Ahmad, G Holland, R Telfer, J Carlson, H Ferguson. Marie Curie Hospice Liverpool, Wirral Hospice St Johns, Woodlands Hospice Liverpool, Willowbrook Hospice, Royal Liverpool University Hospital

10.1136/bmjspcare-2014-000838.44

Introduction Malignant bowel obstruction (MBO) is a recognized complication of advanced pelvic or abdominal malignancy frequently occurring in advanced stages of illness. Suggested incidences in ovarian carcinoma range from 5.5 to $42 \%$ and in colorectal cancer 4.4 to $24 \%$. Where surgery for $\mathrm{MBO}$ is inappropriate medical management may help bring about resolution of the unpleasant symptoms.

Aim(s) and method(s) The aim of this review was to evaluate current evidence and opinion on treatment of symptoms associated with MBO.

A comprehensive systematic review of the literature was undertaken to evaluate the evidence for the medical management of MBO. A questionnaire-based survey was used to establish professional attitudes, opinions and to review current practice.

Results Following exclusions 44 relevant papers were systematically appraised.

There is good evidence for the use of octreotide to reduce secretions and corticosteroids may help bring about resolution of MBO. Ranitidine may also reduce secretions. Venting gastrostomies can alleviate nausea and vomiting with low complication rates and may be considered where prognosis is greater than 2 weeks. No evidence was found for any specific medication to treat vomiting or pain associated with MBO.

In local current practice hyoscine buytlbromide is used first line to treat colic; cyclizine and/or haloperidol to treat vomiting with levomepromazine second line. Corticosteroids and octreotide are routinely prescribed. 